\title{
Seminal plasma regulates endometrial cytokine expression, leukocyte recruitment and embryo development in the pig
}

\author{
S O'Leary, M J Jasper, G M Warnes, D T Armstrong and S A Robertson \\ Department of Obstetrics and Gynaecology and Centre for Reproductive Health, \\ The University of Adelaide, Adelaide, South Australia 5005, Australia
}

Correspondence should be addressed to S O'Leary; Email: sean.oleary@adelaide.edu.au

\begin{abstract}
In pigs, uterine exposure to the constituents of semen is known to increase litter size but the underlying physiological mechanisms remain undefined. Studies in rodents and humans implicate immune modulating moieties in seminal plasma as likely candidates, acting through enhancing the receptivity of the female tract. In this study, the acute and longer term effects of seminal plasma on cytokine expression and leukocyte abundance in the pig endometrium during early pregnancy have been characterised. The reproductive tracts of gonadotrophin-primed pre-pubertal gilts treated with intrauterine infusions of either pooled seminal plasma or phosphate-buffered saline (PBS) were retrieved at $34 \mathrm{~h}$, or on day 5 and day 9 after treatment. Seminal plasma elicited an endometrial inflammatory infiltrate comprised of predominantly macrophages and major histocompatibility complex class $\mathrm{II}^{+}$-activated macrophages and dendritic cells. The abundance of these cells was greatest at the pre-ovulatory $(34 \mathrm{~h})$ time-point and their increase relative to PBS-treated tissues was maintained until day 9 after seminal plasma treatment. Seminal plasma induced the expression of the cytokines, granulocyte macrophage colony-stimulating factor, interleukin-6 and monocyte chemoattractant protein-1, and the eicosanoid-synthesising enzyme cyclo-oxygenase-2. Expression was maximal $34 \mathrm{~h}$ after treatment but altered expression patterns as a consequence of seminal plasma induction persisted through early pregnancy. These changes were accompanied by altered dynamics in pre-implantation embryo development with an increase in the number of embryos and in their viability after seminal plasma treatment. Together, these findings implicate factors in seminal plasma in programming the trajectory of uterine cytokine expression and leukocyte trafficking during early pregnancy and in regulating pre-implantation embryo development in the pig.

Reproduction (2004) 128 237-247
\end{abstract}

\section{Introduction}

Manipulation of female reproductive tract immune parameters has been explored as a means to improve reproductive outcome in livestock species following observations that litter size can be increased in rodents after pre-sensitisation of the uterus with male alloantigens (Beer \& Billingham 1974). Similar effects were observed in pigs when antigenic stimulation by the addition of leukocyte antigens to semen at breeding was reported to increase embryo survival measured in the fifth week of pregnancy (Almlid 1981). Pre-sensitisation of the uterus to sperm and seminal antigens in a previous oestrous cycle also increased litter size in gilts (Murray et al. 1983), and extensive dilution of seminal components by artificial insemination has been implicated in reducing fertility compared with natural mating in pigs (Skjervold 1975).

Recently, studies in rodents and humans have identified immuno-stimulatory molecules present in seminal plasma that influence the uterine environment, through activating a cascade of cytokine- and leukocyte-mediated events that appear to contribute to endometrial receptivity for embryo implantation. In mice, where the effects of semen are best characterised, insemination stimulates a response resembling a classic inflammatory cascade. Factors in seminal plasma activate uterine epithelial expression of proinflammatory cytokines, including granulocyte-macrophage colony-stimulating factor (GM-CSF), interleukin (IL)-6 and several chemokines (Robertson et al. 1992, 1998), to elicit recruitment of inflammatory cells, including macrophages, granulocytes and dendritic cells (De et al. 1991, Robertson et al. 1996a). The inflammatory response is transient and by the time of embryo implantation the post-mating inflammatory response is dissipated. In murine and human seminal plasma, the active component has been identified as transforming growth factor$\beta$ (TGF $\beta$ ) (Tremellen et al. 1998), a cytokine present in 
abundance in the seminal plasma of all mammalian species so far examined (Robertson et al. 2002). The significance of the inflammatory response for pregnancy outcome remains to be fully evaluated but tissue remodelling and immune-regulatory roles for inflammatory leukocytes have been proposed. Activation of T-lymphocytes in draining lymph nodes after mating is consistent with an immune response to antigens in semen (Johansson et al. 2004), potentially facilitating maternal immune tolerance to the conceptus at implantation (Robertson \& Sharkey 2001). Furthermore, cytokines induced by semen target the pre-implantation embryo to regulate blastocyst development. Most notably, GM-CSF is a key determinant of blastomere viability and lineage allocation in the blastocyst (Robertson et al. 2001, Sjoblom et al. 2002).

Strategies that utilise immuno-stimulatory molecules in seminal plasma might provide an effective method for improving reproductive efficiency in the pig and other species. However, such interventions require a better knowledge of the molecular and cellular events elicited by semen. The reproductive tract of the female pig, like that of the mouse, is exposed to semen when the ejaculate is deposited directly into the uterine lumen (Lovell \& Getty 1968). Leukocytes, including macrophages and dendritic cells, neutrophils, eosinophils and lymphocytes are present in the pig endometrium where their numbers fluctuate over the course of the cycle and during pregnancy (Hussein et al. 1983, King 1988), beginning early after natural mating with intact boars (Bischof et al. 1995). Exposure to seminal plasma is implicated in eliciting leukocyte recruitment since qualitative observations show that natural mating with a vasectomised boar may increase the numbers of major histocompatibility complex $(\mathrm{MHC})$ class $\mathrm{II}^{+}$cells in the endometrium, accompanied by changes consistent with lymphocyte activation in draining lymph nodes (Bischof et al. 1994). However, the possible impact of neuroendocrine stimulation as a consequence of the physical act of mating was not precluded in this experiment and the molecular mediators of the effects of seminal plasma were not investigated.

The objective of the current study was to examine more fully the significance of the constituents of seminal plasma in eliciting changes in immune parameters in the porcine reproductive tract. In an experimental strategy devised to avoid physical stimulation, pooled seminal plasma or phosphate-buffered saline (PBS) was administered transcervically to gonadotrophin-primed pre-pubertal gilts prior to ovulation and the acute effects on leukocyte and cytokine parameters during the pre-ovulatory period and over the longer term course of early pregnancy were quantified by immunohistochemistry and RT-PCR respectively. Furthermore, the consequences of seminal plasma exposure for pre-implantation embryo development were examined.

\section{Materials and Methods}

This experiment was conducted at The University of Adelaide Pig and Poultry Production Institute (PPPI) at Roseworthy, Australia. All treatments, housing and retrieval of tissues were approved by The University of Adelaide Animal Ethics Committee. Semen and seminal plasma used for this study were provided by SABOR Pty. Ltd (Clare, Australia).

\section{Experimental design}

A cohort of $32 F_{1}$ (Landrace $\times$ Large White) pre-pubertal gilts at 24 weeks of age were used in these experiments. Oestrus was induced and synchronised using intramuscular injection of $750 \mathrm{IU}$ equine chorionic gonadotrophin (Folligon; Intervet, Boxmeer, The Netherlands) followed $72 \mathrm{~h}$ later by $500 \mathrm{IU}$ human chorionic gonadotrophin (hCG) (Chorulon; Intervet). Gilts were randomly assigned to a $2 \times 3$ factorial arrangement in which they received a $100 \mathrm{ml}$ intrauterine infusion by transcervical catheter of seminal plasma or filter sterilised PBS. Treatments were delivered 1-2 $\mathrm{h}$ after hCG and reproductive tracts were collected from four to six gilts at each of three time-points for each treatment; at $34 \mathrm{~h}$ ('pre-ovulatory'; equating to approximately $6 \mathrm{~h}$ prior to expected ovulation), and on day 5 and day 9 after treatment with seminal plasma or PBS. Gilts in the day- 5 and day- 9 groups in addition received two standard artificial inseminations of $3 \times 10^{9}$ spermatozoa each, the first $2 \mathrm{~h}$ after intrauterine infusion and the second the following morning. The gilts were slaughtered at a commercial abattoir, reproductive tracts were collected and tissue samples were obtained for histochemical and quantitative RT-PCR analysis. Embryos were retrieved from the uterine horns for assessment of cell number (day 5) or diameter (day 9). Four gilts were excluded from the trial, one from each of the 34-h and day-5 time-points and two from the day-9 time-point, all in the PBS-infused control groups, because of endometritis with cystic ovaries ( $34 \mathrm{~h}$ after treatment), uterine infection indicated by increased volume and acidic luminal fluid (day 5), failure to conceive and lameness (one each at day 9).

\section{Seminal plasma treatment and artificial insemination}

For seminal plasma treatment the full ejaculate minus the gel fraction was collected from eight boars of known fertility following at least 5 days of abstinence after a previous collection. The semen was pooled, placed on ice and seminal plasma was collected after centrifugation at $1200 \mathrm{~g}$ at $4{ }^{\circ} \mathrm{C}$ for $20 \mathrm{~min}$. Aliquots of seminal plasma were placed in $100 \mathrm{ml}$ artificial insemination bottles and stored at $-20^{\circ} \mathrm{C}$ until use. The semen used for artificial insemination and the seminal plasma for intrauterine infusions were not necessarily from the same boar. Semen for artificial insemination was prepared, stored and administered according to standard protocols at SABOR Pty. Ltd and PPPI. 


\section{Uterine tissue collection}

As soon as possible after slaughter (10-20 min), the reproductive tracts were retrieved, and the uterine horns were trimmed of mesentery and weighed. Luminal fluid was then drained from the tract and the volume recorded. As a measure of tissue vascularity the relative intensity of colour $(++++=$ red,$+=$ pale pink) of the uterus was recorded.

For immunohistochemistry, full thickness biopsies of uterine tissue were collected at two sites approximately $10-15 \mathrm{~cm}$ proximal to the oviduct and distal to the cervix and placed in optimal cutting temperature compound (OCT compound; Tissue-Tek; Sakura Finetek USA Inc., Torrance, CA, USA), immersion-frozen in liquid nitrogencooled isopentane and stored at $-70{ }^{\circ} \mathrm{C}$ until further processing. Approximately $200 \mathrm{mg}$ endometrial tissue was collected for quantitative RT-PCR analysis, snap frozen in liquid nitrogen and stored at $-70^{\circ} \mathrm{C}$.

\section{Immunohistochemistry}

Immunohistochemical analysis was performed on uterine tissues collected from gilts slaughtered at $34 \mathrm{~h}$, day 5 and day 9 after seminal plasma or PBS treatment. Only gilts confirmed to be pregnant by flushing of viable blastocysts were included in the day-5 and day- 9 treatment groups. Tissue was serially cut into $7 \mu \mathrm{m}$ thick cryostat sections, placed on poly-L-lysine-coated slides (polysineTM microslides; Menzel-Glaser, Braunschweig, Germany) and allowed to air dry. Dried sections were fixed in $96 \%$ ethanol for $10 \mathrm{~min}$ at $4{ }^{\circ} \mathrm{C}$ then washed three times in $1 \times$ PBS. Sections were blocked with $1 \%$ bovine serum albumin in PBS for 2 min and then incubated with primary antibody diluted to $10 \mu \mathrm{g} / \mathrm{ml}$ in $10 \%$ normal pig serum in PBS (PBSNPS) for $2 \mathrm{~h}$ at $4{ }^{\circ} \mathrm{C}$. Primary antibodies included mouse monoclonal antibody reactive with porcine CD45 (MCA1222) (Serotec, Oxford, Oxon, UK), porcine MHC class II (SLA II; MSA3) (Hammerberg \& Schurig 1986) and porcine macrophage antigen (HB142) (American Type Culture Collection, Rockville, MD, USA). Sections were washed in PBS and incubated with biotinylated rabbit antimouse Ig (Dakopatts, Glostrup, Denmark) in PBS-NPS for $60 \mathrm{~min}$ at room temperature. Sections were then washed in PBS and incubated in horseradish peroxidase-conjugated strepavidin (Dakopatts) in PBS-NPS $(30 \mathrm{~min}$, room temperature). Bound antibody was visualised by incubating slides with $0.05 \%$ diaminobenzidine tetrahydrochloride (Sigma Chemical Co., St Louis, MO, USA) in Tris-buffered saline containing $0.1 \%$ hydrogen peroxide $(10 \mathrm{~min}$, room temperature). Slides were counterstained with haematoxylin, dehydrated, cleared in Safsolvent (Ajax Chemicals, Auburn, Australia) and mounted in DPX (BDH Laboratory Supplies, Poole, England). The number of positively stained leukocytes was quantified in ten randomly selected fields from each of two sections collected from the proximal and distal uterine horn of each gilt. Video image analysis was employed using Video Pro software (Leading Edge Software, Adelaide, Australia) with a $10 \times$ objective and
$3.3 \times$ photo eyepiece as previously described (Robertson et al. 1996a). Data are expressed as percent positivity, calculated as the mean area of $3-3^{\prime}$ diaminobenzidine stain as percentage of the area of total stain in the ten fields. Leukocytes were quantified separately for three distinct areas of uterine tissue, including the superficial endometrium (immediately sub-adjacent to the luminal epithelium), endometrial stroma (at least $200 \mu \mathrm{m}$ from the uterine epithelium) and the myometrium (Fig. 1). Repeated measurements of a single test field validated the precision of this method (less than 10\% within-assay variation).

\section{RT-PCR}

cDNA was prepared from endometrial tissue collected from gilts slaughtered at 34 h, day 5 and day 9 after seminal
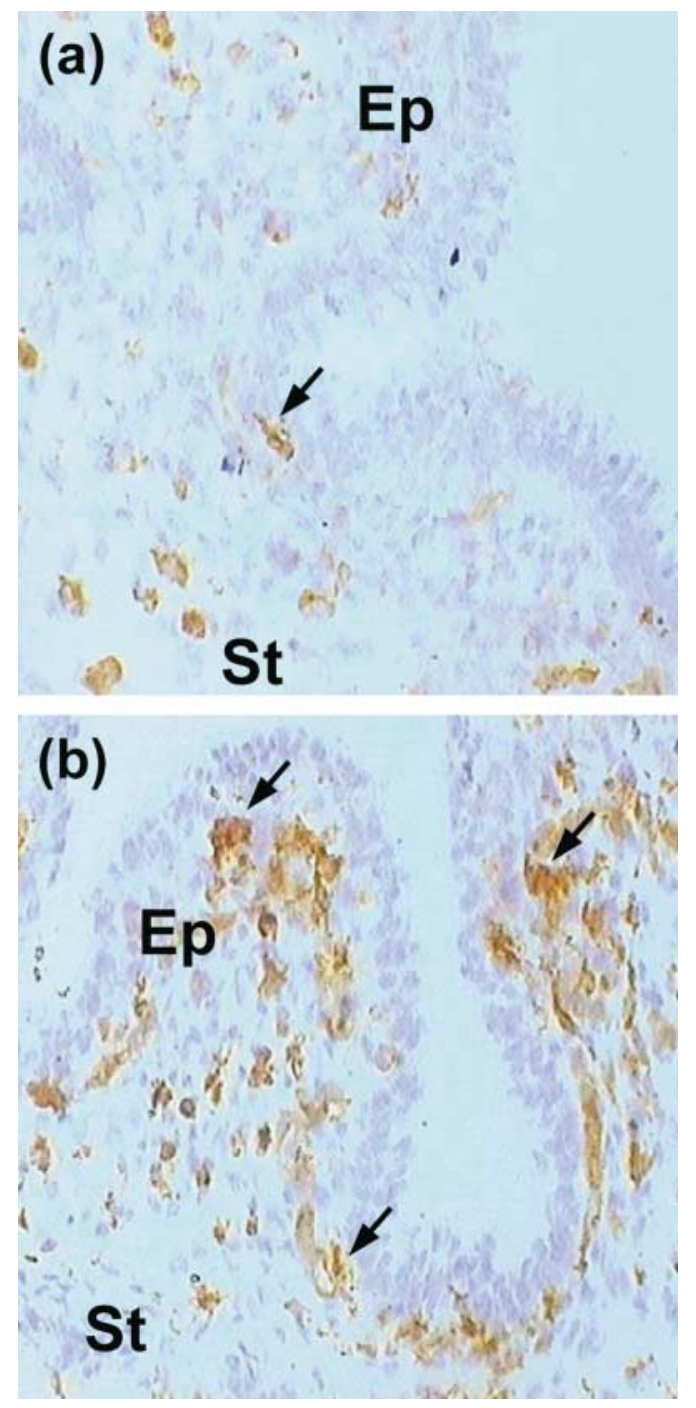

Figure 1 Photomicrograph illustrating immunohistochemical analysis of $\mathrm{CD}_{4} 5^{+}$cells in endometrial tissue from uteri retrieved $34 \mathrm{~h}$ after intrauterine infusion of (a) PBS or (b) seminal plasma. Arrows indicate $\mathrm{CD}_{4} 5^{+}$cells in the superficial endometrium (Ep) and endometrial stroma (St). Magnification $=\times 20$. 
plasma or PBS treatment. Only gilts confirmed to be pregnant by flushing of viable blastocysts were included in the day-5 and day-9 treatment groups. RNA was isolated using RNA Bee solution (Tel-Test, Friendswood, Texas, USA) and treated with RNase-free DNase I (500 IU/ml; $60 \mathrm{~min}$ at $37^{\circ} \mathrm{C}$ ) (Roche, Basel, Switzerland), then first-strand cDNA was reverse transcribed from $1 \mu \mathrm{g}$ RNA employing an expand reverse transcriptase kit $\left(10 \mathrm{~min}\right.$ at $30^{\circ} \mathrm{C}$ then $45 \mathrm{~min}$ at $42^{\circ} \mathrm{C}$ ) (Roche). The cDNA solution was diluted to $100 \mu \mathrm{l}$ and stored at $-20^{\circ} \mathrm{C}$. Primer pairs specific for published Genbank cytokine cDNA sequences were designed using Primer Designer software (Scientific and Educational Software, State Line, PA, USA) or Primer Express software (Applied Biosystems, Foster City, CA, USA). The PCR amplification employed reagents supplied in a $2 \times$ SYBR Green PCR master mix (Applied Biosystems), and each reaction volume $(20 \mu \mathrm{l}$ total) contained $0.5-$ $1.0 \mu \mathrm{M} 5^{\prime}$ and $3^{\prime}$ primer and $3 \mu \mathrm{l}$ cDNA. The negative control included in each reaction consisted of $\mathrm{H}_{2} \mathrm{O}$ substituted for cDNA. PCR amplification was performed in an ABI Prism 5700 sequence detection system (Applied Biosystems) according to the manufacturer's specifications. PCR primers and optimised PCR reaction conditions for each primer pair are listed in Table 1. Reaction products were analysed by dissociation curve profile. Validation experiments were initially performed to examine the efficiencies of each primer pair in the PCR. Cycle threshold values (Ct), defined as the cycle number at which the detected fluorescence exceeds the threshold value, were determined for serial 8-fold dilutions of cDNA in a range of $0.06-30 \mathrm{ng}$ total RNA. For each primer pair, the linearity of detection was confirmed to have a correlation coefficient of $>0.94$ over the detection range, when plotted as Ct versus log of cDNA dilution. Specificity of the PCR was confirmed by detection of a single distinct peak on examination of the dissociation curve profile of the reaction product. In addition, reaction products were analysed by electrophoresis in $2 \%$ agarose gel containing $0.5 \mu \mathrm{g} / \mathrm{ml}$ ethidium bromide and visualised over a u.v. light box. mRNA expression data from experimental tissues was normalised to $\beta$-actin mRNA expression and given as percent of the mean value for the PBS-treated 34-h group using the arithmetic equation $2^{\Delta \mathrm{Ct}} \times 100 / \mathrm{K}$ (Applied Biosystems User
Bulletin No. 2) where $\mathrm{K}$ is the normalising constant. A single 'relative mRNA expression' value for each cytokine mRNA for each individual gilt was calculated as the mean of duplicate cDNA samples from proximal and distal endometrial tissue.

\section{Embryo retrieval and staining}

Embryos were retrieved at autopsy on day 5 and day 9 after treatment by three consecutive $20 \mathrm{ml}$ flushes of Dulbecco's modified Eagle's medium into each uterine horn. Embryos flushed at day 5 were scored as viable when a blastoceol cavity was present, and were scored as viable on day 9 when the spherical blastocyst stage was reached.

Blastocysts collected on day 5 were washed twice in culture media and the zona pellucida was removed by incubation at room temperature for $5 \mathrm{~min}$ in Acid Tyrodes solution (Sigma) followed by incubation at $37^{\circ} \mathrm{C}$ with $0.5 \%$ pronase solution (Sigma) for approximately $3 \mathrm{~min}$ to remove zona pellucidae. After washing in culture media, the blastocysts were stained using $0.1 \mathrm{mM}$ Hoechst 33342 (bisbenzamide; Sigma) for $15 \mathrm{~min}$ and then prepared for microscopic evaluation by fixing under a cover slip in $10 \%$ glycerol. The number of blastomeres were counted under $100 \times$ magnification using u.v. illumination with an Olympus (Melville, NY, USA) BH-2 microscope and the mean number of blastomeres per cohort of embryos for individual gilts was calculated.

Day-9 embryos were washed in PBS, fixed in $1 \%$ paraformaldehyde solution and evaluated directly under light microscopy (Olympus $\mathrm{BH}-2$ ) using a $2.5 \times$ video lens and $4 \times$ objective lens. Using Video Pro software, the horizontal and vertical axes of the approximately spherical embryos were measured and the mean blastocyst diameter per cohort of embryos for individual gilts was calculated.

\section{Statistical analyses}

Values are given as means \pm S.E.M. The effect of treatment on uterine weights, leukocyte abundance and mean embryo size or mean blastomere number was analysed using Student's $t$-test for independent samples, or by oneway ANOVA followed by Bonferroni $t$-test when more

Table 1 PCR primers, reaction conditions, product size, Genbank accession code and primer target sites.

\begin{tabular}{|c|c|c|c|c|}
\hline Primer & PCR conditons ${ }^{\mathrm{a}}$ & $5^{\prime} / 3^{\prime}$ bp position & Genbank $^{b}$ & Size bp \\
\hline$\beta$-actin & $95^{\circ}-15 \mathrm{~s}, 60^{\circ}-1 \mathrm{~min}$ & $80-99 / 474-455$ & U07786 & 395 \\
\hline IL $-1 \beta$ & $95^{\circ}-15 \mathrm{~s}, 57.5^{\circ}-15 \mathrm{~s}, 72^{\circ}-1 \mathrm{~min}$ & $225-242 / 473-456$ & M86725 & 249 \\
\hline IL-6 & $95^{\circ}-15 \mathrm{~s}, 60^{\circ}-1 \mathrm{~min}$ & $598-618 / 698-679$ & M80258 & 101 \\
\hline GM-CSF & $95^{\circ}-20 \mathrm{~s}, 62^{\circ}-20 \mathrm{~s}, 72^{\circ}-1 \mathrm{~min}$ & $137-157 / 316-299$ & U67175 & 180 \\
\hline MCP-1 & $95^{\circ}-20 \mathrm{~s}, 57.5^{\circ}-20 \mathrm{~s}, 72^{\circ}-1 \mathrm{~min}$ & $93-111 / 279-261$ & X79416 & 187 \\
\hline $\mathrm{TNF} \alpha$ & $95^{\circ}-20 \mathrm{~s}, 59^{\circ}-20 \mathrm{~s}, 72^{\circ}-1 \mathrm{~min}$ & $441-459 / 661-644$ & X57321 & 221 \\
\hline COX-2 & $95^{\circ}-15 \mathrm{~s}, 60^{\circ}-1 \mathrm{~min}$ & $951-971 / 1062-1043$ & AF207824 & 112 \\
\hline
\end{tabular}

${ }^{a}$ PCR conditions are given as temperature and duration (minutes or seconds) for the melt, annealing and extension phases comprising each cycle.

${ }^{\mathrm{b}} \mathrm{NCBI}$ Genbank accession number.

MCP-1, monocyte chemoattractant protein-1; TNF $\alpha$, tumour necrosis factor- $\alpha$; COX-2, cyclo-oxygenase-2. 
than two treatment groups were compared. Cytokine mRNA expression data was analysed using Kruskal-Wallis one-way ANOVA and Mann-Whitney rank sum test. Statistical significance was inferred at $P<0.05$. All statistical analyses were performed using SPSS 11.0 for Windows.

\section{Results}

\section{Effect of seminal plasma on uterine weight, luminal fluid volume and vascularity}

To examine the effect of seminal plasma on uterine immune parameters, uterine tracts recovered $34 \mathrm{~h}$ after treatment ('pre-ovulatory'; equating to approximately $6 \mathrm{~h}$ prior to expected ovulation), were evaluated initially for gross measurements of an inflammatory response (Table 2). Compared with tracts retrieved from PBS-treated gilts, the tracts from seminal plasma-treated gilts were on average $68 \%$ heavier $(P=0.03)$ and contained 3.5-fold more luminal fluid $(P=0.19)$. This effect was short lived, since uterine weights and luminal fluid content were not significantly different in gilts at day 5 and day 9 after treatment (data not shown). In addition, seminal plasma treatment influenced the number of leukocytes, principally granulocytes, infiltrating into the uterine lumen with a 5.4-fold increase in the mean leukocyte content of luminal fluid from seminal plasma-treated gilts $(P=0.01)$. Visual inspection of the colour of the uterine tract suggested increased uterine vascularity after seminal plasma exposure in tracts retrieved from pre-ovulatory gilts (Table 2).

\section{Effect of seminal plasma on uterine leukocytes}

The acute and longer term effects of seminal plasma on uterine leukocyte abundance and distribution were examined in tissues retrieved at $34 \mathrm{~h}$ and on day 5 and day 9 after seminal plasma or PBS treatment by immunohistochemical analysis using monoclonal antibodies reactive with all leukocytes (CD45; MCA1222), macrophages (HB142) and MHC class II expressed by activated macrophages and/or dendritic cells (MSA3). There was heterogeneity in the spatial distribution of leukocytes at all time-points, with mean leukocyte positivity approximately

Table 2 The effect of seminal plasma (SP) treatment on uterine weight, luminal fluid volume, total luminal fluid leukocyte number and vascularity in gilts at $34 \mathrm{~h}$ after treatment. Values are means \pm S.E.M.

\begin{tabular}{lcc}
\hline & PBS $(n=3)$ & SP $(n=4)$ \\
\hline Uterine weight $(\mathrm{g})$ & $79 \pm 5$ & $116 \pm 8 *$ \\
Luminal fluid volume $(\mathrm{ml})$ & $6.7 \pm 1.2$ & $23.2 \pm 9.2$ \\
Luminal fluid leukocytes $($ per $\mu \mathrm{l})$ & $1220 \pm 330$ & $6540 \pm 2300 * *$ \\
Vascular index ${ }^{\mathrm{a}}$ (median) & ++ & ++++ \\
\hline
\end{tabular}

${ }^{a}$ Vascularity: + , pale pink; ++++ , red.

$* P=0.03, * * P=0.01$. 2-fold greater in the superficial endometrium and endometrial stroma than in the myometrium.

In 34-h (pre-ovulatory) uterine tissue, leukocyte infiltration was greater after intrauterine seminal plasma exposure, with $31 \%, 47 \%$ and $77 \%$ increases in percent positivity of CD45 staining in the superficial endometrium, endometrial stroma and myometrial tissue respectively compared with tissues from the PBS-treated group $(P<0.01)$ (Fig. 2). The infiltrating leukocytes were comprised predominantly of macrophages with $62-85 \%$ increases in these cells in each tissue compartment, and to a lesser extent in MHC class II positive cells which were increased by $30-45 \%$ in each compartment.

The effects of seminal plasma on uterine leukocyte abundance persisted for several days, with seminal plasma treatment resulting in longer term retention of leukocytes. In PBS-treated gilts, the abundance of CD45 leukocytes in the superficial endometrium was depleted 3.5-fold by day 5 compared with pre-ovulatory tissues; however, leukocytes recruited after exposure to seminal plasma persisted at similar densities such that the mean percent positivity values for macrophages and class II MHC positive cells were 3.7-fold and 2.7-fold greater at day 5 after seminal plasma exposure compared with PBS controls (both $P<0.001$ ). The effects of seminal plasma were diminished but still evident at day 9, when the mean percent positivity in CD45 staining was 31\% higher in superficial endometrium from seminal plasma-treated gilts $(P<0.01)$. Furthermore, a gradual shift in the ratio of HB142 positive macrophages to MHC class II-activated macrophages and dendritic cells was evident over the course of early pregnancy, regardless of seminal plasma exposure, with approximately equal proportions shifting to a 2.3-fold excess of the latter cells by day 9. Similar effects of seminal plasma on leukocyte retention and lineage distribution were seen in the deeper endometrial stroma and myometrium (Fig. 2).

\section{Effect of seminal plasma on uterine cytokine expression}

PCR primers were designed and synthesised for a panel of cytokines known to be induced in murine endometrial tissue after insemination. Quantitative RT-PCR analysis was undertaken in tissue collected at $34 \mathrm{~h}$ and on day 5 and day 9 after treatment with seminal plasma or PBS to evaluate the identity and patterns of expression of cytokines regulating the inflammatory response to seminal plasma. AII PCR primer sets generated amplicons of the expected size with no evidence of contaminating DNA (Fig. 3). Endometrial exposure to seminal plasma induced expression of GMCSF, IL-6 and MCP-1 mRNA in pre-ovulatory tissue, with 5-fold, 9.3-fold and 2.1-fold increases over mean values from PBS-treated animals respectively (Fig. 4a, b and f). The increase in pro-inflammatory cytokine expression was short lived, with expression of mRNA encoding GM-CSF declining by day $5(P=0.01)$ and remaining low at day 9 
(a)

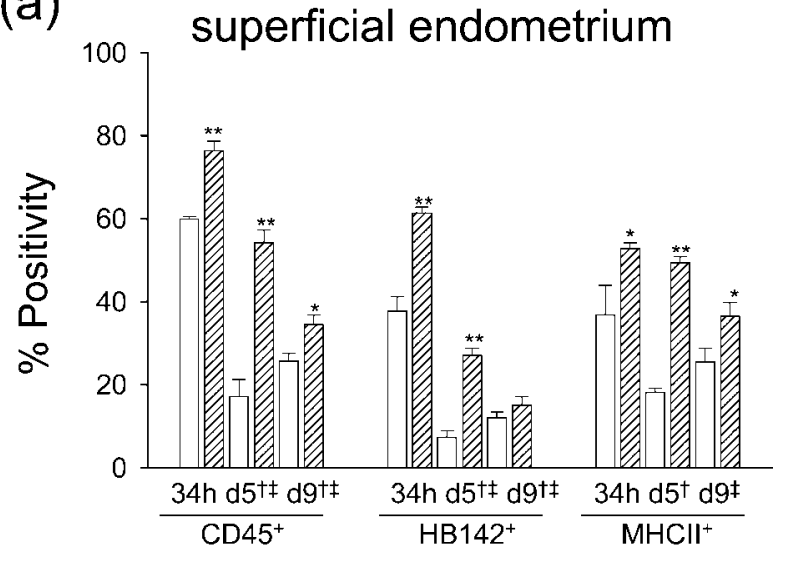

(b)

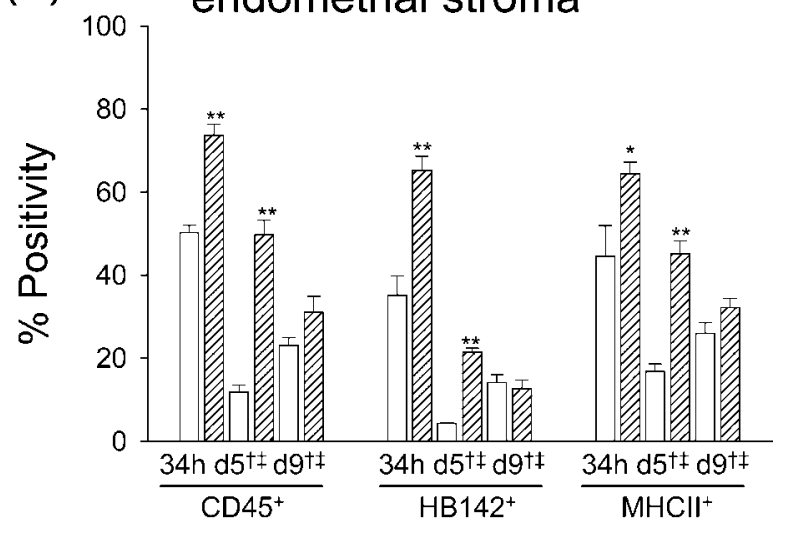

(c)

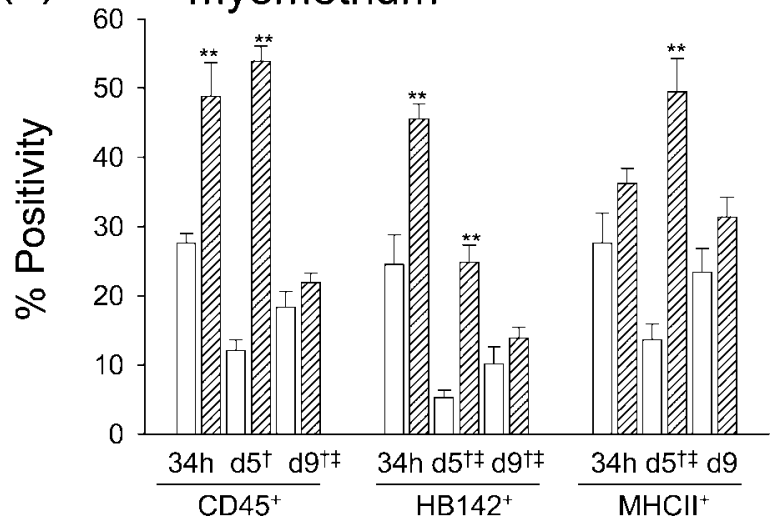

Figure 2 The effect of seminal plasma treatment on the abundance of leukocytes in the (a) superficial endometrium, (b) endometrial stroma and (c) myometrium in gilts at $34 \mathrm{~h}$, day 5 and day 9 after treatment. Immunohistochemical analysis was performed using monoclonal antibodies reactive with all leukocytes (CD45), macrophages (HB142) and MHC class II (MHCII; MSA3). Positively stained cells were quantified by Video Pro analysis. Data are means \pm S.E.M. \% positivity in PBS-treated groups (open bars) or seminal plasma-treated groups (hatched bars). Data were compared using ANOVA followed by Bonferroni $t$-test. ${ }^{*} P<0.05,{ }^{* *} P<0.001$ compared with PBS-treated group for the same time-point; ${ }^{\dagger} P<0.05$ compared with the 34-h time-point for data within the PBS-treated group; ${ }^{\ddagger} P<0.05$ compared with the $34-\mathrm{h}$ time-point for data within the seminal plasma-treated group. after treatment. MCP-1 mRNA showed a similar pattern of synthesis. Expression of TNF $\alpha$ and IL-1 $\beta$ mRNAs were unresponsive to seminal plasma but, like the other pro-inflammatory cytokines, were expressed in lower abundance on day 5 and day 9 (Fig. 4c and e). In contrast, IL-6 mRNA expression remained high in seminal plasmatreated tissues from $34 \mathrm{~h}$ through day 5 but then declined 9.8-fold between day 5 and day 9 (Fig. 4 b).

The distinction in cytokine expression between seminal plasma and PBS treatment groups persisted through to the day 5 and day 9 time-points. In contrast to the expression profile in seminal plasma-treated tissue, GM-CSF mRNA in PBS-treated tissue did not decline between $34 \mathrm{~h}$ and day 5 , when the mean value was 3.2-fold higher than in seminal plasma-treated tissues $(P=0.01)$. Similarly, IL-6 mRNA expression in PBS-treated tissues remained high over the course of the evaluation period and failed to decline by day 9 . MCP-1 expression was also elevated on day 9 in PBS-treated tissues compared with seminal plasma-treated tissues.

Expression of mRNA encoding the eicosanoid-synthesising enzyme COX-2 followed a pattern similar to that of GM-CSF mRNA with an initial 4.5-fold increase in mean expression in response to seminal plasma treatment (Fig. 4d). Upregulation was transient and by day 5 expression was reduced 7.8-fold $(P=0.01)$ and expression remained low at day 9. The expression profile was distinctly different in gilts treated with PBS, where expression increased on day 5 relative to the 34 -h time-point $(P=0.05)$ and mean relative mRNA expression was 6-fold greater than in seminal plasma-treated gilts $(P=0.04)$.

\section{The effect of seminal plasma on embryo development}

To investigate whether the cytokine and leukocyte changes induced by seminal plasma were associated with differences in embryo development, embryos were retrieved from uteri at day 5 and day 9 after treatment. More embryos were flushed from the tracts of seminal plasmatreated gilts at both day 5 and day 9, and the differences reached statistical significance when values from both days were combined, with a $33 \%$ increase in the total number of embryos in gilts treated with seminal plasma $(P=0.03$; Table 3). Exposure to seminal plasma resulted in an increase in the proportion of viable embryos from $77 \%$ to $91 \%$, leading to a $58 \%$ increase in the number of viable embryos recovered from gilts after seminal plasma treatment (day 5 and day 9 data combined; $P=0.03$; Table 3). Embryo development was compared between the two treatment groups by evaluating the mean number of blastomeres in embryos at day 5 after treatment and embryo diameter at 9 days after treatment (Table 3 and Fig. 5). Seminal plasma did not influence blastomere number at day 5 after treatment but did have a significant effect at day 9 after treatment, at which time embryos recovered from seminal plasma-treated gilts were on average $40 \%$ smaller in diameter than their control counterparts $(P<0.001)$. 


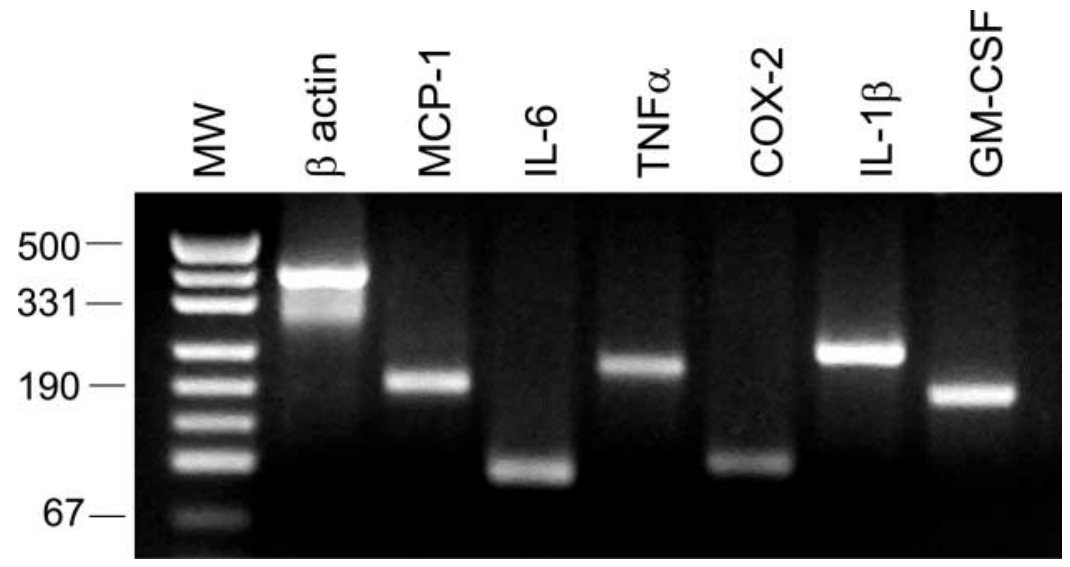

Figure 3 RT-PCR amplification products using primer sets specific for $\beta$-actin, MCP-1, IL-6, TNF $\alpha$, COX-2, IL-1 $\beta$ and GM-CSF mRNAs. Lane MW, molecular weight marker $p U C 19$.

\section{Discussion}

Embryonic and fetal mortality is a major limitation on litter size in pigs where between $30 \%$ and $40 \%$ of fertilised ova do not result in a live-born piglet (Dzuik 1987). Pregnancies conceived by artificial insemination generally fare less well than natural matings and interventions involving exposure to seminal constituents have met with some success in reducing early loss (Skjervold 1975, Murray \& Grifo 1986). However, the mechanisms through which factors in semen contribute to establishing an optimal uterine environment have not previously been investigated. The experiments described in this study have shown that factors in the plasma fraction of semen interact (a)

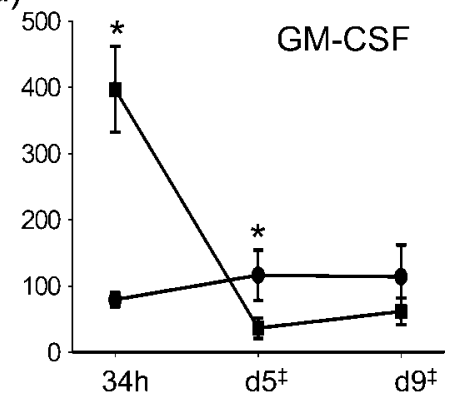

(c)

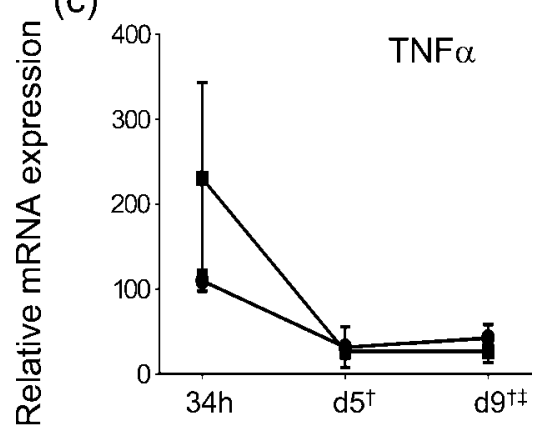

(e)

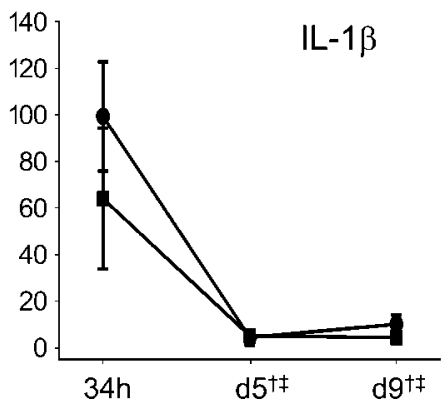

(b)

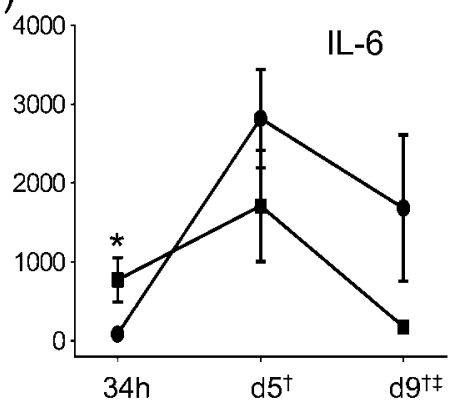

(d)

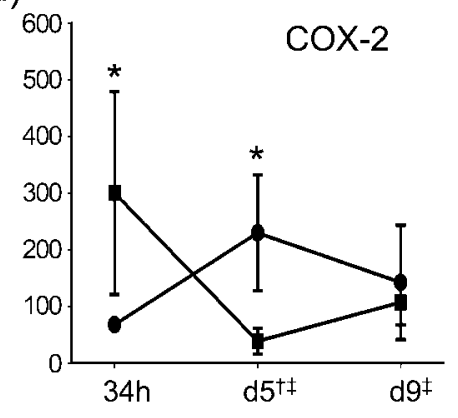

(f)

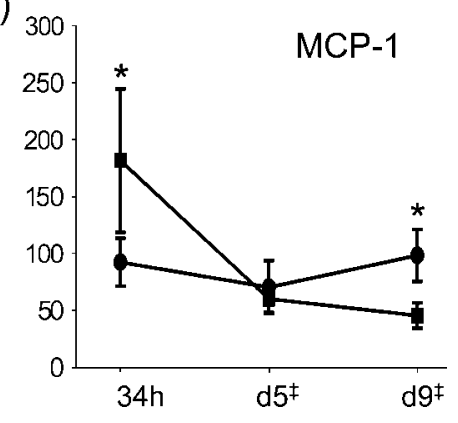

Figure 4 The effect of seminal plasma treatment on endometrial cytokine mRNA expression in gilts at $34 \mathrm{~h}, 5$ days (d5) and 9 days (d9) after treatment. Data are means \pm S.E.M. relative mRNA expression of (a) GM-CSF, (b) IL-6, (c) TNF $\alpha$, (d) COX-2, (e) IL-1 $\beta$ and (f) MCP-1 in the seminal plasma-treated group (面) $(n=4-6$ per time-point) or PBS-treated group $(\bullet)$ ( $n=3-5$ per time-point). Relative mRNA expression is calculated by normalising data to $\beta$-actin mRNA expression and expressed as percent of the mean value in the 34-h PBS-treated group. Data were compared by Kruskal-Wallis followed by Mann-Whitney $U$ test. ${ }^{*} P<0.05$ compared with the same time-point in the PBS-treated group; ${ }^{\dagger} P<0.05$ compared with the 34-h time-point for data within the PBS-treated group; ${ }^{\ddagger} P<0.05$ compared with the 34 -h time-point for data within the seminal plasma-treated group. 
Table 3 The effect of seminal plasma (SP) treatment on the number of embryos recovered, and their blastomere number and diameter after retrieval from gilts at 5 and 9 days after treatment respectively.

\begin{tabular}{|c|c|c|}
\hline & PBS & SP \\
\hline Total embryos on day $5(n)^{\mathrm{a}}$ & $8.7 \pm 1.0(4)$ & $12.1 \pm 1.3(7)$ \\
\hline Total embryos on day $9(n)^{\mathrm{a}}$ & $9.2 \pm 0.9(5)$ & $11.8 \pm 1.6(6)$ \\
\hline Total embryos (day $5+$ day 9) $(n)^{\text {a }}$ & $9.0 \pm 0.6(9)$ & $12.0 \pm 1.0(13) *$ \\
\hline Viable embryos on day $5(\%)^{a}$ & $6.5 \pm 2.3(75 \%)$ & $10.5 \pm 1.6(87 \%)$ \\
\hline Viable embryos on day $9(\%)^{a}$ & $7.2 \pm 2.0(78 \%)$ & $11.3 \pm 1.4(96 \%)$ \\
\hline Viable embryos (day $5+$ day 9$)(\%)^{a}$ & $6.9 \pm 1.4(77 \%)$ & $10.9 \pm 1.0(91 \%) *$ \\
\hline Blastomere number on day $5(n)^{b}$ & $38 \pm 3(36)$ & $34 \pm 4(95)$ \\
\hline Diameter $(\mu \mathrm{m})$ on day $9(n)^{\mathrm{b}}$ & $497 \pm 40(46)$ & $284 \pm 23 * *(71)$ \\
\hline
\end{tabular}

${ }^{a}$ Data are means \pm S.E.M. number of embryos flushed per gilt, with viable embryos defined as those with a blastoceol cavity at day 5 or spherical blastocyst at day 9.

${ }^{b}$ Data are means \pm S.E.M. blastomere number or embryo diameter.

$* P=0.03$ and $* * P<0.001$ compared with PBS-treated group (Student's $t$-test).

with the endometrium to induce changes in cytokine expression and leukocyte infiltration that persist at least for the first 9 days of early pregnancy and appear to influence pre-implantation embryo development.

The cascade of cellular and molecular events induced by seminal plasma are characteristic of an inflammatory response and, in terms of the pro-inflammatory cytokines induced and the leukocyte populations recruited, the response closely parallels that seen in mice after insemination (Robertson et al. 1996a). Most prevalent amongst the infiltrating cells were macrophages and MHC class $\mathrm{II}^{+}$ cells in the endometrium, and granulocytes in the luminal fluid. Previous studies in pigs have noted an increase in MHC class $\mathrm{II}^{+}$cells in the subepithelial endometrial tissue after mating with intact or vasectomised boars (Bischof et al. 1994, Engelhardt et al. 1996). These authors also described a concurrent endometrial hypertrophy, consistent with our observations on uterine vascularity, luminal fluid content and weight. Overt inflammatory indices subsided by day 5 , perhaps because of an inhibitory role for increasing progesterone which acts to reduce expression of inflammatory mediators during early pregnancy in the mouse (Robertson et al. 1996b) and human (Critchley et al. 1996). The current study confirms and extends the previous observations (Bischof et al. 1994, Engelhardt et al.
1996) by clearly demonstrating that factors in seminal plasma, rather than the mating event itself, initiate the inflammatory cascade. Moreover, by quantifying the cellular changes, we have confirmed that both macrophages and $\mathrm{MHC}$ class $\mathrm{II}^{+}$cells increase. Recent studies in mice (Hudson-Keenihan \& Robertson 2004) suggest that MHC class $\mathrm{II}^{+}$macrophages and dendritic cells mature from precursor cells recruited into the endometrium from the blood as MHC class $\mathrm{II}^{-}$monocytes. The current finding that the ratio of $\mathrm{MHC}$ class $\mathrm{II}^{+}$cells to macrophages increases in endometrial tissues over the course of early pregnancy is consistent with a similar differentiation sequence in pigs.

The role of the post-mating inflammatory response, and whether or how it may impact on pregnancy success, is not clear. Initially, a seminal plasma-induced infiltration of leukocytes into the uterine lumen and tissue may have a role in clearing the uterus of redundant spermatozoa and micro-organisms introduced at mating. However, there is evidence from studies in macrophage-deficient rodents (Cohen et al. 1999) to implicate a more proactive role for macrophages in promoting pregnancy success. Since macrophages secrete an array of extracellular matrix-degrading enzymes and can influence cell growth, differentiation and function (Hunt \& Robertson 1996), one likely action is in remodelling the architecture of the
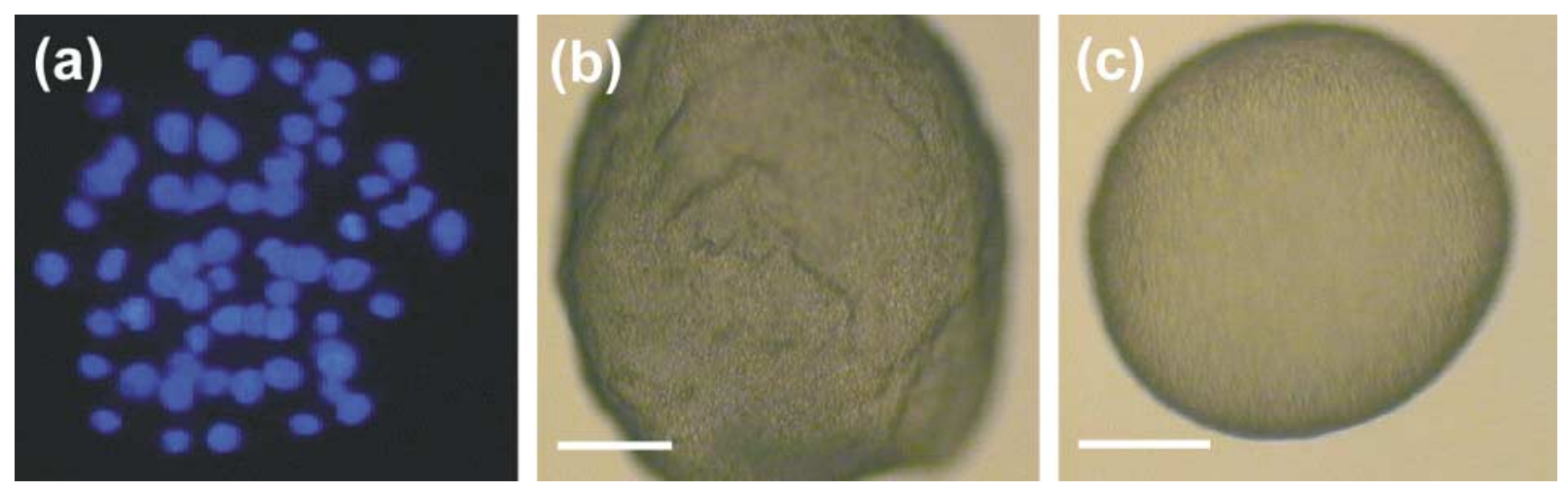

Figure 5 The effect of seminal plasma on embryo development. Representative embryos are shown. Embryos were retrieved on (a) day 5 after treatment and incubated with Hoescht stain to enable blastomere enumeration (100x magnification) or (b) on day 9 after treatment to enable measurement of diameters in PBS-treated gilts and (c) in seminal plasma-treated gilts. Scale bar $=50 \mu \mathrm{m}$. 
uterine tissue or the adhesive qualities of the luminal epithelium to accommodate the conceptus.

Increases in MHC class $\mathrm{II}^{+}$antigen-presenting cell abundance and maturation would also be expected to influence the immune response to male transplantation antigens and thus post-implantation placental and fetal development. In mice, uterine antigen-presenting cells traffic to the lymph nodes draining the uterus inducing hypertrophy (Johansson et al. 2004). The result is activation of T-lymphocytes associated with induction of immune tolerance to paternal antigens in semen, potentially facilitating maternal immune accommodation of the implanting embryo (Robertson \& Sharkey 2001). Similarly in the pig, upregulation of MHC class II and IL-2 receptor expression in uterine lymph nodes is observed following mating (Bischof et al. 1994), suggesting that similar mechanisms are operating to induce immune responses to seminal antigens and prepare for later exposure to the same antigens associated with the developing placenta.

In mice, the key mediators that drive the cellular infiltrate after seminal plasma exposure are pro-inflammatory cytokines expressed in epithelial cells, particularly GMCSF and IL-6 which increase 20-fold and 200-fold respectively (Robertson et al. 1992). Several chemokines targeting macrophages and granulocytes are also induced within hours of mating (Wood et al. 1997, Pollard et al. 1998, Robertson et al. 1998) and it is likely that these cytokines function synergistically to orchestrate extravasation and spatial positioning as well as the activation phenotypes of inflammatory cells. The current study has suggested that expression of these same pro-inflammatory mediators are induced in the porcine uterus after interaction between seminal plasma and uterine cells, with GM-CSF, IL-6 and MCP-1 each induced after seminal plasma exposure. Their temporal pattern of expression parallels the mouse, with a transient pulse in expression then subsequent decline.

Of considerable interest was the finding that the consequences of seminal plasma exposure persist over the course of the pre-implantation period, with reduced expression of GM-CSF and the pro-inflammatory mediator COX-2 5 days after treatment with seminal plasma and extended semen, and reduced expression of MCP-1 9 days later. The mechanisms by which seminal components influence the longer term pattern of cytokine expression are not clear. In mice, the inflammatory response terminates in association with rising progesterone levels (McMaster et al. 1993, Robertson et al. 1996b) raising the question of whether altered steroid hormone synthesis might account for the effect in pigs. Our recent observations of elevated progesterone secretion after seminal plasma treatment provides some support for this proposal (O'Leary et al. 2001, 2002). Early pregnancy factor, a member of the chaperonin 10 family of molecules with potent immunosuppressive properties, has been shown to be increased after mating sows with vasectomised boars (Koch \& Ellendorff 1985) and might also contribute to faster resolution of endometrial inflammation.
This fluctuating cytokine expression pattern reflects the dynamics of endometrial change during this critical phase in early pregnancy and might be expected to provide at a molecular level the selective forces that result in such a high and variable level of embryo mortality at this time (Dzuik 1987). Differential cytokine expression would occur after natural mating versus artificial insemination with diluted semen. Additionally, variance between boars in the active moieties regulating endometrial cytokine expression might contribute to between boar differences in fertility beyond those attributable to sperm parameters (Rozeboom et al. 2000). The active component of seminal plasma in mice is TGF $\beta$ (Tremellen et al. 1998). The content of TGF $\beta$ in porcine seminal plasma is similar to the high levels measured in human and murine seminal plasma of $100-200 \mathrm{ng} / \mathrm{ml}$ (Robertson et al. 2002, S O'leary, DT Armstrong \& SA Robertson, unpublished observations) but it remains to be proven whether the effects described in this study are attributable to TGF $\beta$ or other molecules in boar seminal plasma.

Uterine environment is a well-recognised determinant of the quality of embryo development in pigs (Pope et al. 1990, Vallet et al. 2002). The physiological significance of seminal plasma in the conditioning of the uterine environment was evident in increased numbers of viable embryos and altered embryo growth over the 9-day period after prior exposure to seminal plasma. The increase in embryo survival presumably reflects indirect effects of seminal constituents on the reproductive tract environment acting to reduce early embryo mortality. Somewhat surprisingly, this was associated with significant reduction in the size of embryos retrieved from the tract 9 days after treatment. Seminal plasma is likely to impact on embryo development through direct effects on local epithelial cell cytokine synthesis, and indirectly through eliciting altered secretion of embryotrophic factors stemming from functional changes in endometrial tissue remodelling or altered immune environment. Cytokines secreted into the uterine lumen target the developing embryo directly. GMCSF in particular has been shown to be an important embryotrophic molecule, and its enhanced expression in response to seminal plasma is likely to increase the GMCSF reservoir associated with glycosaminoglycans in the epithelial glycocalyx (Roberts et al. 1988). The growthpromoting effects of GM-CSF were first identified in mouse blastocysts (Robertson et al. 1991), where GM-CSF acts to prevent apoptosis and to increase the number of viable inner cell mass cells (Robertson et al. 2001). GMCSF is also reported to increase blastocyst development in the cow (de Moraes \& Hansen 1997) and in humans (Sjoblom et al. 2002), and to stimulate secretion of interferon- $\tau$ in ovine embryos (Imakawa et al. 1993).

Several other cytokines can influence pre-implantation embryo development, acting both to promote and restrict blastocyst growth and to co-ordinate synchronous development with the maternal tract (Jaeger et al. 2001). Whether retarded blastocyst expansion might be linked 
with enhanced embryo survival is unclear, but it is relevant that similar mechanisms are purported to increase embryo survival in Meishan pigs. Compared with commercial breeds, Meishan pigs have smaller embryos with fewer cells during the blastocyst stage (Rivera et al. 1996), and unique uterine-embryo signalling in Meishans is believed to underpin a maternal ability to control embryo growth resulting in the prolificacy of this breed (Christenson et al. 1993).

The physiological significance of COX-2 induction by seminal plasma is of considerable interest. In contrast to the constitutively active isoform COX-1, COX-2 is induced in endometrial tissues by a variety of pro-inflammatory cytokines and microbial products (Jones et al. 1997). The expression profile of COX-2 in the endometrium follows a similar pattern to GM-CSF and IL-6 with increased expression just prior to expected ovulation and a reduction in expression as pregnancy progresses.

COX-2 catalyses the formation of prostaglandin (PG) $F_{2 \alpha}$ and $\mathrm{PGE}_{2}$. PGs have pleiotrophic effects in pregnancy and have the potential to influence maternal immune responses (Kelly \& Critchley 1997), embryo development (Claus et al. 1987) and ovarian function (Armstrong 1981, Christenson et al. 1994). Most notable is the role of $\mathrm{PGF}_{2 \alpha}$ and $\mathrm{PGE}_{2}$ in the maternal recognition of pregnancy, particularly in view of studies indicating the importance of $\mathrm{PGF}_{2 \alpha}$ synthesised by the uterine endometrium (Bazer \& Thatcher 1977) and potentially transferred to the ovary by a counter-current mechanism facilitated by close apposition of the uterine venous net to the ovarian artery (Krzymowski et al. 1989). In non-mated gilts $\mathrm{PGF}_{2 \alpha}$ is the major eicosanoid but in mated gilts peak PG secretion occurs earlier and $\mathrm{PGE}_{2}$ predominates, antagonising the luteolytic effects of $\mathrm{PGF}_{2 \alpha}$ (Christenson et al. 1994). The increase in COX-2 mRNA described in this study raises the tantalising possibility of a new role for seminal plasma in amplifying uterine synthesis of anti-luteolytic prostaglandins, but additional experiments will be required to dissect its contribution from that of other early pregnancy mediators.

In summary, the results of this study have shown that specific constituents of seminal plasma regulate the cytokine and leukocyte environment in early pregnancy and begin to provide a molecular explanation for the beneficial effects of semen exposure in increasing litter size in pigs. Further studies are required to identify the active components in seminal plasma and to determine whether these can be exploited to improve reproductive outcome as constituents of synthetic semen extenders in artificial insemination regimes in the pig industry.

\section{Acknowledgements}

The authors thank R R C Kamai for assistance with immunohistochemical analysis and the PPPI piggery staff for the care of animals. This study was supported by Australian Pork Limited, NHMRC (Australia) and Canadian Institute of Health Research.

\section{References}

Almlid T 1981 Does enhanced antigenicity of semen increase the litter size in pigs? Journal of Animal Breeding and Genetics 98 $1-10$.

Armstrong DT 1981 Prostaglandins and follicular functions. Journal of Reproduction and Fertility 62 283-291.

Bazer FW \& Thatcher WW 1977 Theory of maternal recognition of pregnancy in swine based on estrogen controlled endocrine versus exocrine secretion of prostaglandin F2alpha by the uterine endometrium. Prostaglandins 14 397-400.

Beer AE \& Billingham RE 1974 Host responses to intra-uterine tissue, cellular and fetal allografts. Journal of Reproduction and Fertility Supplement 21 59-88.

Bischof RJ, Lee CS, Brandon MR \& Meeusen E 1994 Inflammatory response in the pig uterus induced by seminal plasma. Journal of Reproductive Immunology 26 131-146.

Bischof RJ, Brandon MR \& Lee CS 1995 Cellular immune responses in the pig uterus during pregnancy. Journal of Reproductive Immunology $29161-178$.

Christenson RK, Vallet JL, Leymaster KA \& Young LD 1993 Uterine function in Meishan pigs. Journal of Reproduction and Fertility Supplement 48 279-289.

Christenson LK, Farley DB, Anderson LH \& Ford SP 1994 Luteal maintenance during early pregnancy in the pig: role for prostaglandin E2. Prostaglandins $4761-75$.

Claus R, Hoang-Vu C, Ellendorff F, Meyer HD, Schopper D \& Weiler U 1987 Seminal oestrogens in the boar: origin and functions in the sow. Journal of Steroid Biochemistry 27 331-335.

Cohen PE, Nishimura K, Zhu L \& Pollard JW 1999 Macrophages: important accessory cells for reproductive function. Journal of Leukocyte Biology 66 765-772.

Critchley HO, Kelly RW, Lea RG, Drudy TA, Jones RL \& Baird DT 1996 Sex steroid regulation of leukocyte traffic in human decidua. Human Reproduction $112257-2262$.

De M, Choudhuri R \& Wood GW 1991 Determination of the number and distribution of macrophages, lymphocytes and granulocytes in the mouse uterus from mating through implantation. Journal of Leukocyte Biology 50 252-262.

Dzuik PJ 1987 Embryonic loss in the pig: an enigma. Manipulating pig production I, pp 28-39. Proceedings of the Inaugural Conference of Australian Pig Science Association. Eds JL Barnett. Melbourne: Frankland Pty Ltd.

Engelhardt H, Small MR \& King GJ 1996 Exposure of pigs to seminal plasma at estrus recruits leukocytes to the uterine epithelium. Biology of Reproduction 54 Abstract 476.

Hammerberg C \& Schurig GG 1986 Characterization of monoclonal antibodies directed against swine leukocytes. Veterinary Immunology and Immunopathology 11 107-121.

Hudson-Keenihan SN \& Robertson SA 2004 Diversity in phenotype and steroid hormone dependence in dendritic cells and macrophages in the mouse uterus. Biology of Reproduction 70 $1562-1572$.

Hunt JS \& Robertson SA 1996 Uterine macrophages and environmental programming for pregnancy success. Journal of Reproductive Immunology 32 1-25.

Hussein AM, Newby TJ \& Bourne FJ 1983 Immunohistochemical studies of the local immune system in the reproductive tract of the sow. Journal of Reproductive Immunology 5 1-15.

Imakawa K, Helmer SD, Nephew KP, Meka CS \& Christenson RK 1993 A novel role for GM-CSF: enhancement of pregnancy specific interferon production, ovine trophoblast protein-1. Endocrinology 132 1869-1871.

Jaeger LA, Johnson GA, Ka H, Garlow JG, Burghardt RC, Spencer TE \& Bazer FW 2001 Functional analysis of autocrine and paracrine signalling at the uterine-conceptus interface in pigs. Reproduction Supplement 58 191-207. 
Johansson M, Bromfield JJ, Jasper MJ \& Robertson SA 2004 Semen activates the female immune response during early pregnancy in mice. Immunology 112 290-300.

Jones RL, Kelly RW \& Critchley HO 1997 Chemokine and cyclooxygenase-2 expression in human endometrium coincides with leukocyte accumulation. Human Reproduction 12 1300-1306.

Kelly RW \& Critchley HO 1997 Immunomodulation by human seminal plasma: a benefit for spermatozoon and pathogen? Human Reproduction 12 2200-2207.

King GJ 1988 Reduction in uterine intra-epithelial lymphocytes during early gestation in pigs. Journal of Reproductive Immunology 14 41-46.

Koch E \& Ellendorff F 1985 Detection of activity similar to that of early pregnancy factor after mating sows with a vasectomized boar. Journal of Reproduction and Fertility 74 39-46.

Krzymowski T, Stefanczyk-Krzymowska S \& Koziorowski M 1989 Counter current transfer of PGF2 alpha in the mesometrial vessels as a mechanism for prevention of luteal regression in early pregnancy. Acta Physiologica Polonica $4023-34$.

Lovell JW \& Getty R 1968 Fate of semen in the uterus of the sow: histologic study of endometrium during the 27 hours after natural service. American Journal of Veterinary Research 29 609-625.

McMaster MT, Dey SK \& Andrews GK 1993 Association of monocytes and neutrophils with early events of blastocyst implantation in mice. Journal of Reproduction and Fertility 99 561-569.

de Moraes AA \& Hansen PJ 1997 Granulocyte-macrophage colonystimulating factor promotes development of in vitro produced bovine embryos. Biology of Reproduction 57 1060-1065.

Murray FA \& Grifo APJ 1986 Intrauterine infusion of killed semen to increase litter size in gilts. Journal of Animal Science 62 187-190.

Murray FA, Grifo AP Jr \& Parker CF 1983 Increased litter size in gilts by intrauterine infusion of seminal and sperm antigens before breeding. Journal of Animal Science 56 895-900.

O'Leary S, Armstrong DT \& Robertson SA 2001 Intrauterine seminal plasma increases ovarian steroidogenesis during early pregnancy in the pig. In Australasian Pig Science Association (APSA), vol. VIII, p 190. Ed. PD Cranwell. Adelaide, South Australia: APSA.

O'Leary S, Robertson SA \& Armstrong DT 2002 The influence of seminal plasma on ovarian function in pigs - a novel inflammatory mechanism? Journal of Reproductive Immunology $\mathbf{5 7}$ 225-238.

Pollard JW, Lin EY \& Zhu L 1998 Complexity in uterine macrophage responses to cytokines in mice. Biology of Reproduction $\mathbf{5 8}$ $1469-1475$

Pope WF, Xie S, Broermann DM \& Nephew KP 1990 Causes and consequences of early embryonic diversity in pigs. Journal of Reproduction and Fertility Supplement 40 251-260.

Rivera RM, Youngs CR \& Ford SP 1996 A comparison of the number of inner cell mass and trophectoderm cells of preimplantation Meishan and Yorkshire pig embryos at similar developmental stages. Journal of Reproduction and Fertility 106 111-116.

Roberts R, Gallagher J, Spooncer E, Allen TD, Bloomfield F \& Dexter TM 1988 Heparan sulphate bound growth factors: a mechanism for stromal cell mediated haemopoiesis. Nature 332 376-378.

Robertson SA \& Sharkey DJ 2001 The role of semen in induction of maternal immune tolerance to pregnancy. Seminars in Immunology 13 243-254.

Robertson SA, Lavranos TC \& Seamark RF 1991 In vitro models of the maternal fetal interface. In The Molecular and Cellular
Immunobiology of the Maternal-Fetal Interface, pp 191-206. Eds TG Wegmann, E Nisbett-Brown \& TG Gill. New York: Oxford University Press.

Robertson SA, Mayrhofer G \& Seamark RF 1992 Uterine epithelial cells synthesize granulocyte-macrophage colony-stimulating factor and interleukin- 6 in pregnant and nonpregnant mice. Biology of Reproduction 46 1069-1079.

Robertson SA, Mau VJ, Tremellen KP \& Seamark RF 1996a Role of high molecular weight seminal vesicle proteins in eliciting the uterine inflammatory response to semen in mice. Journal of Reproduction and Fertility 107 265-277.

Robertson SA, Mayrhofer G \& Seamark RF $1996 b$ Ovarian steroid hormones regulate granulocyte-macrophage colony-stimulating factor synthesis by uterine epithelial cells in the mouse. Biology of Reproduction 54 183-196.

Robertson SA, Allanson M \& Mau VJ 1998 Molecular regulation of uterine leukocyte recruitment during early pregnancy in the mouse. Trophoblast Research 11 101-119.

Robertson SA, Sjoblom C, Jasper MJ, Norman RJ \& Seamark RF 2001 Granulocyte-macrophage colony-stimulating factor promotes glucose transport and blastomere viability in murine preimplantation embryos. Biology of Reproduction 64 1206-1215.

Robertson SA, Ingman WV, O'Leary S, Sharkey DJ \& Tremellen KP 2002 Transforming growth factor beta - a mediator of immune deviation in seminal plasma. Journal of Reproductive Immunology 57 109-128.

Rozeboom KJ, Troedsson MHT, Hodson HH, Shurson GC \& Crabo BG 2000 The importance of seminal plasma on the fertility of subsequent artificial inseminations in swine. Journal of Animal Science 78 443-448.

Sjoblom C, Wikland M \& Robertson SA 2002 Granulocyte-macrophage colony-stimulating factor (GM-CSF) acts independently of the beta common subunit of the GM-CSF receptor to prevent inner cell mass apoptosis in human embryos. Biology of Reproduction 67 1817-1823.

Skjervold H 1975 Comparison of litter size by use of natural and by artificial mating. Journal of Animal Breeding and Genetics 92 252-259.

Tremellen KP, Seamark RF \& Robertson SA 1998 Seminal transforming growth factor beta1 stimulates granulocyte-macrophage colony-stimulating factor production and inflammatory cell recruitment in the murine uterus. Biology of Reproduction $\mathbf{5 8}$ $1217-1225$.

Vallet JL, Leymaster KA \& Christenson RK 2002 The influence of uterine function on embryo and fetal survival. Journal of Animal Science $\mathbf{8 0}$ E115-E125.

Wood GW, Hausmann E \& Choudhuri R 1997 Relative role of CSF-1, MCP-1/JE and RANTES in macrophage recruitment during successful pregnancy. Molecular Reproduction and Development $\mathbf{4 6}$ 62-69.

Received 5 January 2004

First decision 27 February 2004

Revised manuscript received 3 May 2004

Accepted 11 May 2004 